\title{
THE
}

\section{Evolution of Upper Jaw Protrusion Mechanisms in Elasmobranchs}

\author{
Cheryl Wilga \\ University of Rhode Island, cwilga@uri.edu \\ Robert E. Hueter \\ Peter C. Wainwright \\ Philip J. Motta
}

Follow this and additional works at: https://digitalcommons.uri.edu/bio_facpubs

Terms of Use

All rights reserved under copyright.

\section{Citation/Publisher Attribution}

Cheryl D. Wilga, Robert E. Hueter, Peter C. Wainwright, Philip J. Motta; Evolution of Upper Jaw Protrusion Mechanisms in Elasmobranchs, Integrative and Comparative Biology, Volume 41, Issue 6, 1 December 2001, Pages 1248-1257, https://doi.org/10.1093/icb/41.6.1248

Available at: https://doi.org/10.1093/icb/41.6.1248

This Article is brought to you for free and open access by the Biological Sciences at DigitalCommons@URI. It has been accepted for inclusion in Biological Sciences Faculty Publications by an authorized administrator of DigitalCommons@URI. For more information, please contact digitalcommons-group@uri.edu. 


\title{
Evolution of Upper Jaw Protrusion Mechanisms in Elasmobranchs ${ }^{1}$
}

\author{
Cheryl D. Wilga, ${ }^{2, *}$ Robert E. Hueter, $\dagger$ Peter C. Wainwright $\ddagger$ And \\ PHILIP J. MOTTA§ \\ *Department of Biological Sciences, University of Rhode Island, 100 Flagg Rd., \\ Kingston, Rhode Island 02881 \\ †Center for Shark Research, Mote Marine Laboratory, 1600 Ken Thompson Parkway, \\ Sarasota, Florida 34236 \\ $\$$ Section of Evolution and Ecology, University of California, One Shields Ave., Davis, California 95616 \\ $\S$ Department of Biology, University of South Florida, Tampa, Florida 33620
}

\begin{abstract}
SYNOPSIS. Upper jaw protrusion is a prominent component of the feeding mechanism in most elasmobranchs and has received considerable attention over the years. In this paper, we review what is known of muscle activity during prey capture in elasmobranchs, particularly that of upper jaw protrusion, and evaluate the extent to which functional modifications have evolved through changes in anatomy or patterns of muscle activity. To date, motor activity during feeding has been documented in only four species of elasmobranchs, although they represent the three major elasmobranch groups: Galea (typical sharks); Squalea (dogfish sharks); and Batoidea (skates and rays). Our efforts show that while muscles involved in cranial elevation and lower jaw depression and elevation show a conserved pattern of motor activity and function across species, other muscles show a more variable history. Our observations of elasmobranch upper jaw protrusion mechanisms suggest a mosaic of character changes over the course of evolution that involve anatomical changes in all cases and modifications of muscle activation patterns in some cases. During the evolution of feeding mechanisms of elasmobranchs, there have been two structural changes incorporating a pre-existing motor pattern to yield an unmodified kinematic profile, the original preorbitalis and the descendent preorbitalis. One additional instance of structural modification is accompanied by an alteration in the motor pattern leading to a change in movement pattern, the levator palatoquadrati.
\end{abstract}

\section{INTRODUCTION}

Understanding how musculoskeletal systems have been modified in the course of animal history is a central theme in functional morphology. Behaviors of interest to functional morphologists, such as feeding, can often be characterized by a common kinematic pattern. Evolutionary changes in a selected kinematic pattern may occur by several pathways: as a result of anatomical alterations in the structural elements that perform them, by changes in the activation pattern of muscles that operate the skeletal system, or by changes at both of these levels (Lauder, 1991; Reilly and Lauder, 1992; Lauder and Shaffer, 1993; Smith, 1994b;

\footnotetext{
${ }^{1}$ From the Symposium Motor Control of Vertebrate Feeding: Function and Evolution presented at the Annual Meeting of the Society for Integrative and Comparative Biology, 3-7 January 2001, at Chicago, Illinois.

${ }^{2}$ E-mail: cwilga@uri.edu
}

Wainwright and Turingan, 1997; Friel and Wainwright, 1998, 1999; Wilga et al., 2000). Functional studies on the head of bony fishes and salamanders suggest that differences in feeding behavior most frequently result from modifications in the musculoskeletal anatomy and that the general sequence of motor activity tends to be phylogenetically conserved (Shaffer and Lauder, 1985a, $b$; Wainwright and Lauder, 1986; Sanderson, 1988; Wainwright, 1989; Wainwright et al., 1989; Westneat and Wainwright, 1989; Lauder and Shaffer, 1993; Friel and Wainwright, 1998; Smith, 1994a; Wilga et al., 2000). However, other studies have shown that details of the motor pattern, such as intensity and specific timing of muscle activity, may differ among species and that these changes can be a central component of behavioral evolution (Liem, 1979, 1989; Lauder, 1983; Friel and 
Wainwright, 1998, 1999). Given these generalities from research on bony fishes and some salamanders, we review recent studies on the evolution of feeding systems in Chondrichthyes, the sister group to all other living gnathostome vertebrates.

Upper jaw protrusion in elasmobranchs provides an ideal system for studying the evolution and function of a musculoskeletal system because it is an important element of feeding behavior in most species (Motta and Wilga, 2001) and because the anatomy of the jaw musculature has a rich history. Physical subdivision and structural alteration have been implicated in the evolution of the muscles involved in protruding the upper jaw in elasmobranchs (Daniel, 1934; Moss, 1972; Compagno, 1988; Shirai, 1996). Upper jaw protrusion in elasmobranchs occurs when the palatoquadrate cartilage moves anteroventrally away from the cranium as the jaws close on the prey. Numerous functions for protrusion of the upper jaw in sharks have been proposed: more efficient biting and manipulation of the prey; gouging of the upper jaw into large prey; a versatile yet hydrodynamic subterminal mouth; reorienting of the teeth for increased grasping ability; nearly simultaneous closure of the upper and lower jaws; greater speed of jaw closure (Springer, 1961; Alexander, 1967; Moss, 1972, 1977; Tricas and McCosker, 1984; Frazzetta and Prange, 1987; Frazzetta, 1994; Motta et al., 1997; Wilga and Motta, 1998a, b, 2000; Pretlow-Edmonds, 1999).

Although the mechanics of feeding and upper jaw protrusion have been studied in only a few elasmobranch species, several different mechanisms have been described. These differences have been attributed (Moss, 1972, 1977; Motta and Wilga, 1995, 1999; Wilga and Motta, 1998a, b, 2000) to differences among taxa in cranial development and myology (Vetter, 1874, 1878; Tiesing, 1895; Marion, 1905; Luther, 1909; Allis 1917, 1923; Daniel, 1934; Edgeworth, 1935; Lightoller, 1939; Marinelli and Strenger, 1959; Nobiling, 1977; Compagno, 1988) and have had a profound effect on the mechanics of jaw protrusion in sharks. In this paper, we review what is known of muscle activity during feeding, particularly that associated with upper jaw protrusion, and evaluate the extent to which evolutionary modifications have come about through changes in anatomy or patterns of muscle activation.

\section{General Features of Shark Feeding}

Sharks employ a variety of mechanisms for capturing prey: biting, ram feeding, and suction feeding. During biting, sharks open and close the jaws directly onto large prey, usually gouging out a chunk of the prey in the process, as typified in the white shark, Carcharodon carcharias (Galea: Lamniformes) (Tricas and McCosker, 1984). Other sharks use a ram mechanism in which the jaws are opened widely as the shark overswims and engulfs the prey, such as observed in bonnethead (Sphyrna tiburo), swell (Cephaloscyllium ventriosum), blacknose (Carcharhinus acronotus), blacktip (Carcharhinus limbatus), lemon (Negaprion brevirostris), Caribbean reef sharks (Carcharhinus perezi) (all Galea) (Frazzetta and Prange, 1987; Motta et al., 1997; Ferry-Graham, 1997, 1998; Wilga and Motta, 2000; Motta and Wilga, 2001). Still others use suction to draw the prey into the mouth, including nurse sharks (Ginglymostoma cirratum), wobbegongs (Orectolobus maculates), spiny dogfish (Squalus acanthias), Atlantic guitarfish (Rhinobatos lentiginosus), leopard sharks (Triakis semifasciata), horn sharks (Heterodontus francisci), and even whale sharks (Rhincodon typus) (Wu, 1994; Clark and Nelson, 1997; FerryGraham, 1998; Wilga and Motta, 1998a, b; Pretlow-Edmonds, 1999; unpublished data, P.J.M.; Robinson, 1999). Many elasmobranchs may use a combination of these behaviors, such as the spiny dogfish, S. acanthias, which uses all three mechanisms variably to capture prey depending on prey size (Wilga, 1997, 1998a). However, existing data on motor activity during feeding in elasmobranchs are insufficient to evaluate how the motor pattern is modified for use in different capture mechanisms.

Detailed studies of cranial functional morphology have recently been conducted utilizing electromyography and high-speed video on four elasmobranch species that were sampled from major groups of Chon- 
drichthyes: lemon sharks, Negaprion brevirostris (Galea: Carcharhiniformes); bonnethead sharks, Sphyrna tiburo (Galea: Carcharhiniformes); spiny dogfish, Squalus acanthias (Squalea: Squaliformes); and Atlantic guitarfish, Rhinobatos lentiginosus (Batoidea: Rhinobatoidei) (Motta et al., 1997; Wilga and Motta, 1998a, b, 2000). Schematic diagrams illustrating the mechanisms for head and jaw kinematics in these species are shown in Figure 1. The muscles involved with cranial elevation and both lower jaw depression and elevation show a similar motor pattern in the four species during feeding, while there is greater diversity in the motor control of muscles controlling upper jaw protrusion and retraction. The expansive phase of mouth opening is characterized by activity in the coracomandibularis and epaxialis muscles that function to depress the lower jaw and elevate the cranium respectively. In the compressive phase, lower jaw elevation by the quadratomandibularis muscle and upper jaw protrusion by the preorbitalis muscle adducts the jaws. Peak hyoid depression, effected by the coracohyoideus and coracoarcualis muscles, is attained after peak gape. The jaws are then returned to their resting position in the recovery phase by activation of the levator hyomandibularis muscle. This anterior-to-posterior timing of head and jaw movements during feeding is thought to generate pressure changes directing the flow of water into the mouth and occurs widely in aquatic feeding vertebrates (Tricas and McCosker, 1984; Lauder, 1985; Bemis and Lauder, 1986; Frazzetta and Prange, 1987; Reilly and Lauder, 1992; Ferry-Graham, 1997; Lauder and Shaffer, 1993).

\section{UPPER JAW PROTRUSION}

Several mechanisms for protruding the upper jaw have been described in elasmobranchs, though most species exhibit only one or two mechanisms. When the details of protrusion are mapped onto a phylogeny it becomes clear that there have been several structural modifications in the history of elasmobranch jaw protrusion mechanisms (e.g., Wilga et al., 2000). Our investigations suggest that action of the preor-
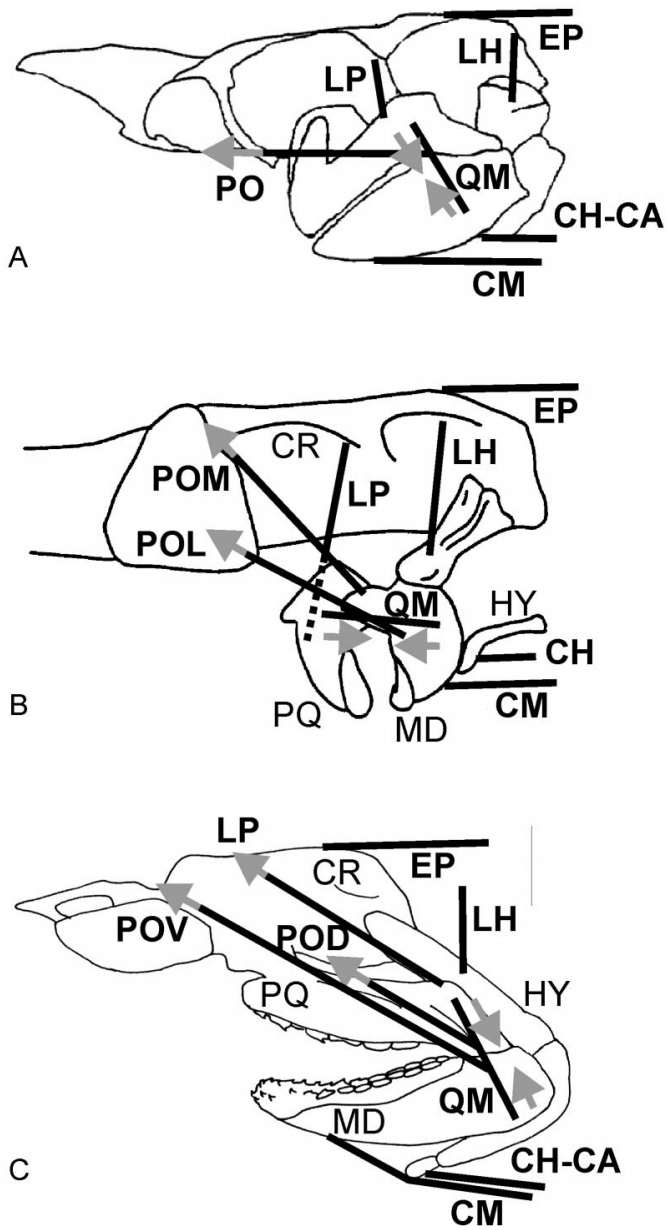

FIG. 1. Muscles involved in cranial and jaw movements during feeding in elasmobranchs. Lateral views of A) spiny dogfish, Squalus acanthias; B) Atlantic guitarfish, Rhinobatos lentiginosus; C) bonnethead shark, Sphyrna tiburo (also representative of lemon sharks, Negaprion brevirostris) (after Wilga and Motta, 1998a, b, 2000). Gray arrows indicate muscle activity during upper jaw protrusion and lower jaw elevation. Note that the quadratomandibularis is also active during upper jaw protrusion. CA, coracoarcualis; $\mathrm{CH}$, coracohyoideus; CM, coracomandibularis; CR, cranium; EP, epaxialis; HY, hyoid apparatus; LH, levator hyomandibularis; LP, levator palatoquadrati; MD, mandible or lower jaw; PO, preorbitalis; POD, dorsal preorbitalis; POL, lateral preorbitalis; POM, medial preorbitalis; POV, ventral preorbitalis; PQ, palatoquadrate or upper jaw; QM, quadratomandibularis medial implant.

bitalis muscle represents the ancestral protrusion mechanism (PO Fig. 1; Wilga and Motta, 1998a, b, 2000), although this muscle is subdivided in some lineages. In these 
latter groups the preorbitalis (ventral) retains the function of protruding the upper jaw, but the descendent muscle (dorsal preorbitalis) undergoes a change in insertion and retains the motor pattern and function of the undivided muscle. In contrast, a shift in the origin of the levator palatoquadrati muscle has been accompanied by a change in motor pattern and a change in function in carcharhinids (Motta et al., 1997; Wilga and Motta, 2000). Finally, the quadratomandibularis muscle may effect upper jaw protrusion by adducting the upper and lower jaws.

\section{The ancestral protrusion mechanism}

Basal sharks have a single undivided preorbitalis muscle, homologous to the ventral preorbitalis muscle, which extends from the nasal capsule to the quadratomandibularis muscle (Marion, 1905; Daniel, 1934; Compagno, 1977, 1988; Shirai, 1996). This muscle effects protrusion by pulling the posterior region of the upper jaw anteriorly causing the anterior region to slide ventrally down a vertical groove in the cranium (Motta et al., 1997; Wilga and Motta, 2000) (PO and POV Fig. 1). This role of the preorbitalis muscle in protruding the upper jaw is indicated by motor activity recorded simultaneously with video during feeding in Squalus acanthias (single preorbitalis), Negaprion brevirostris (ventral preorbitalis), and Sphyrna tiburo (ventral preorbitalis) (Motta et al., 1997; Wilga and Motta, 1998a, 2000). Character optimization suggests that the single undivided preorbitalis muscle is the ancestral protrusion mechanism in elasmobranchs (Fig. 3, \#1; Motta et al., 1997; Wilga and Motta, 1998a, b, 2000). If so, then physical subdivision of this muscle into dorsal and ventral divisions did not alter the ancestral function and motor pattern. The ability to protrude the upper jaw during feeding has been observed in most elasmobranchs, including species belonging to such basal groups as hexanchids (Wilga, 1997; Motta and Wilga, 2001). Recent phylogenetic hypotheses place chlamydoselachiform, hexanchiform, and squaliform sharks as basal elasmobranch groups (Compagno, 1973, 1977; De Carvalho, 1996; Shirai, 1996). These groups all possess a single preorbitalis muscle that is similar in morphology to the ventral division in those with subdivided muscles, i.e., extending between the nasal capsule and palatoquadrate.

In contrast to the ventral preorbitalis, the lateral preorbitalis muscle, which is analogous (homology has not been determined yet) to the ventral preorbitalis of sharks, in $R$. lentiginosus may function to elevate the lower jaw (Figs. 1, 2). The lateral preorbitalis inserts directly onto the mandible from the nasal region and contraction is believed to elevate the relatively lighter lower jaw rather than to depress the heavier cranium (Wilga and Motta, 1998b). The lateral preorbitalis is active during jaw closing in $R$. lentiginosus, a phase in which upper jaw protrusion and lower jaw elevation occur simultaneously (Fig. 2). However, it is unlikely that the upper jaw is protruded by the lateral preorbitalis since batoids lack an articulation between the upper jaw and cranium that would force the upper jaw to move along the cranium as is seen in sharks. Furthermore, batoids protrude the upper jaw directly ventrally rather than anteroventrally as in sharks.

\section{A novel protrusion mechanism}

The preorbitalis muscle is physically subdivided in carcharhiniform sharks with the ventral muscle retaining the original morphology and function while the dorsal muscle has a modified insertion (Moss, 1972; Compagno, 1988) but retains the motor pattern and function of protruding the upper jaw (Fig. 3, black square). The dorsal preorbitalis extends from the quadratomandibularis muscle and inserts onto the upper jaw assisting protrusion by pulling the upper jaw ventrally away from the cranium as the ventral preorbitalis pulls the upper jaw anteriorly causing it to slide ventrally along a groove in the cranium (Motta et al., 1997; Wilga and Motta, 2000) (Fig. 1). Accordingly, the dorsal preorbitalis muscle is active during upper jaw protrusion in $N$. brevirostris and S. tiburo (Motta et al., 1997; Wilga and Motta, 2000). The dorsal preorbitalis muscle represents a second mechanism for protruding the upper jaw in carcharhiniform sharks and is considered a de- 


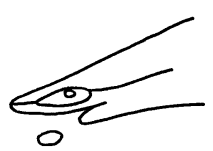

A

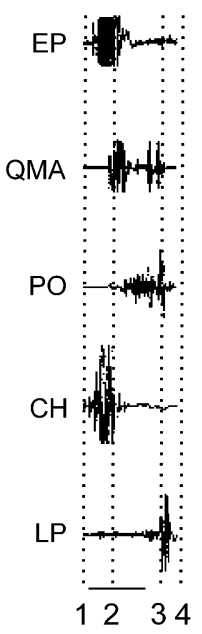

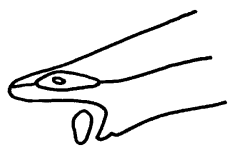

B

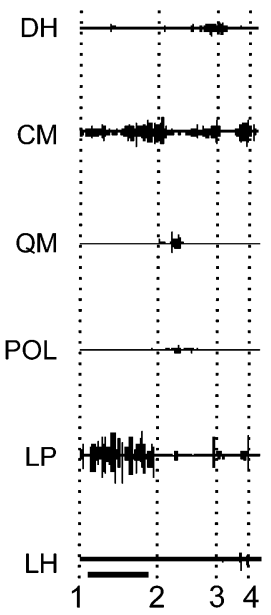

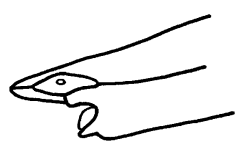
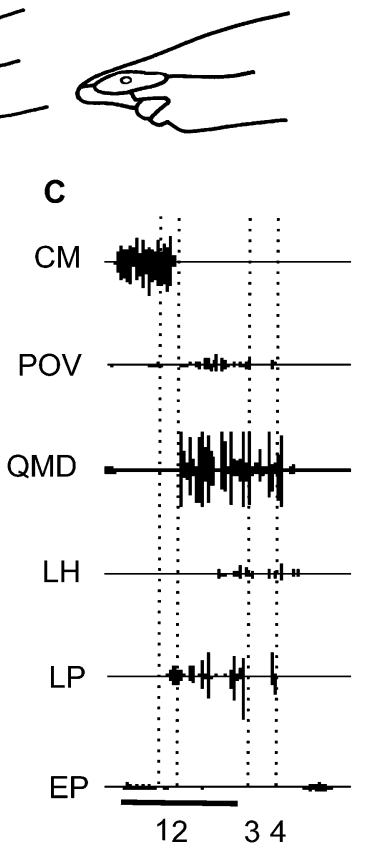

FIG. 2. Motor patterns during feeding in A) a spiny dogfish, Squalus acanthias suction feeding; B) an Atlantic guitarfish, Rhinobatos lentiginosus suction feeding; and C), a bonnethead shark, Sphyrna tiburo ram feeding. Lemon sharks Negaprion brevirostris are similar to C. Numbered dotted lines indicate 1) the start of the expansive phase (head elevation, lower jaw and hyoid depression), 2) the start of the compressive phase (lower jaw elevation and upper jaw protrusion), 3) the start of the recovery phase (jaw retraction), and 4) complete jaw closure respectively. Outline shows a representative sequences corresponding to the numbered dotted lines during ram feeding in $S$. tiburo. Black bars indicate $200 \mathrm{msec}$. In $N$. brevirostris, the POD is active during upper jaw protrusion similar to POV. (after Motta et al., 1997; Wilga and Motta, 1998a, b, 2000). Abbreviations as in Figure 1. DH, depressor hyomandibularis, QMA, quadratomandibularis anterior implant, QMD, quadratomandibularis, dorsal implant.

rived characteristic of the order (Moss, 1972; Compagno, 1988).

\section{A modified protrusion mechanism}

The ancestral carcharhiniform function of the levator palatoquadrati muscle, estimated by reconstructing trait history in the light of phylogenetic hypotheses (Nakaya, 1975; Compagno, 1988; Shirai, 1996), is to elevate the upper jaw. A dorsoventrally oriented levator palatoquadrati, originating from the postorbital region and inserting onto the posterior palatoquadrate is the ancestral condition, an arrangement present in batoids, squalean and lamniform sharks (Marion, 1905; Luther, 1909; Edgeworth, 1935; Moss, 1972, 1977; Nakaya, 1975; Compagno, 1988; Shirai, 1996) (Fig. 4, \#1). In two squalean elasmobranchs, $S$. acanthias and $R$. lentiginosus, motor activity in the levator palatoquadrati occurs during retraction of the upper jaw but never during protrusion of the upper jaw (Fig. 2) (Wilga and Motta, 1998a, b). This indicates that the levator palatoquadrati functions in elevation of the upper jaw in elasmobranchs with the ancestral morphology of this muscle (Fig. 4, gray squares).

Carcharhinid sharks possess a third mechanism for upper jaw protrusion that involves modification of the levator palatoquadrati muscle (Nakaya, 1975; Compagno, 1988). The origin of the levator palatoquadrati has shifted to the antorbital and supraorbital region of the cranium such that it is now well anterior to the insertion on the posterior end of the palatoquadrati and results in a more horizontal orientation of the muscle, compared to the more vertical orientation of the general condition (Fig. 1, A, 


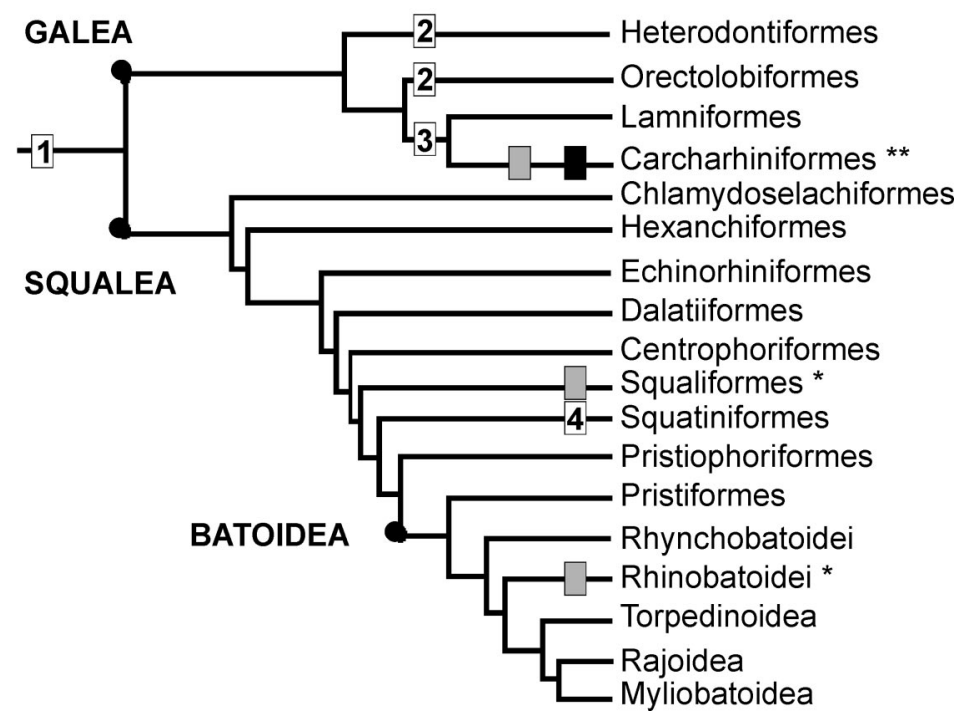

FIG. 3. Elasmobranch cladogram after Shirai (1996) with morphology and motor activity of the ventral preorbitalis muscle mapped onto it according to Wiley et al. (1991). Black dots indicate the base of Galea, Squalea, and Batoidea. Numbered boxes indicate morphological differences: 1, anteroposterior orientation, inserts on quadratomandibularis in sharks, lower jaw in batoids; 2, dorsoventral orientation, inserts on lower jaw; 3, additional dorsal division in anteroposterior orientation, inserts on quadratomandibularis; 4 , muscle absent. Colored boxes indicate function: gray, ventral preorbitalis active during upper jaw protrusion; black, dorsal preorbitalis active during upper jaw protrusion. Since upper jaw protrusion and lower jaw elevation occur at the same time during jaw closure, it is unknown which kinematic event the preorbitalis mediates in groups with morphology 2 and 4. Species with kinematic and electromyographic data used in this analysis are marked by an asterisk indicating the group to which the species belongs and the number of species examined per group.

B vs. C) (Nakaya, 1975; Compagno, 1988; Shirai, 1996). This progressive shift in orientation of the levator palatoquadrati muscle within sharks of the family carcharhinidae has altered the function (Nakaya, 1975; Compagno, 1988; Wilga, 1997; Wilga and Motta, 1998a, b). The levator palatoquadrati muscle is active during upper jaw protrusion in the carcharhinid sharks $N$. brevirostris and S. tiburo (Fig. 2c; Fig. 4, black square) (Motta et al., 1997; Wilga and Motta, 2000). The role of the levator palatoquadrati muscle appears to be protrusion of the upper jaw in some carcharhinid sharks and elevation of the upper jaw in other elasmobranchs, strikingly different functions. The levator palatoquadrati muscle has undergone a morphological transformation that results in an alteration in function. Accordingly, this transformation from the ancestral to the derived condition can be traced among carcharhinid taxa (Nakaya, 1975). However, much work needs to be done in order to determine at what morpho- logical level this functional transformation took place among carcharhiniform sharks.

\section{The jaw adductor as a protrusion mechanism}

The quadratomandibularis extends between the palatoquadrate and mandible and may assist in protruding the upper jaw in all elasmobranchs. During development in Scyllium and Heterodontus the preorbitalis muscle separates from the anterior edge of the presumptive quadratomandibularis and extends anteriorly (Edgeworth, 1935). Together these two muscles form a functional unit called the adductor mandibulae complex (Edgeworth, 1935; Lightoller, 1939). Thus, protrusion of the upper jaw by the preorbitalis muscle may be developmentally and functionally linked to the quadratomandibularis. Supporting this, adduction of the jaws, upper jaw protrusion, and quadratomandibularis and preorbitalis activity occur during jaw closure in Squalus acanthias, $N$. brevirostris, $R$. lentiginosus and 


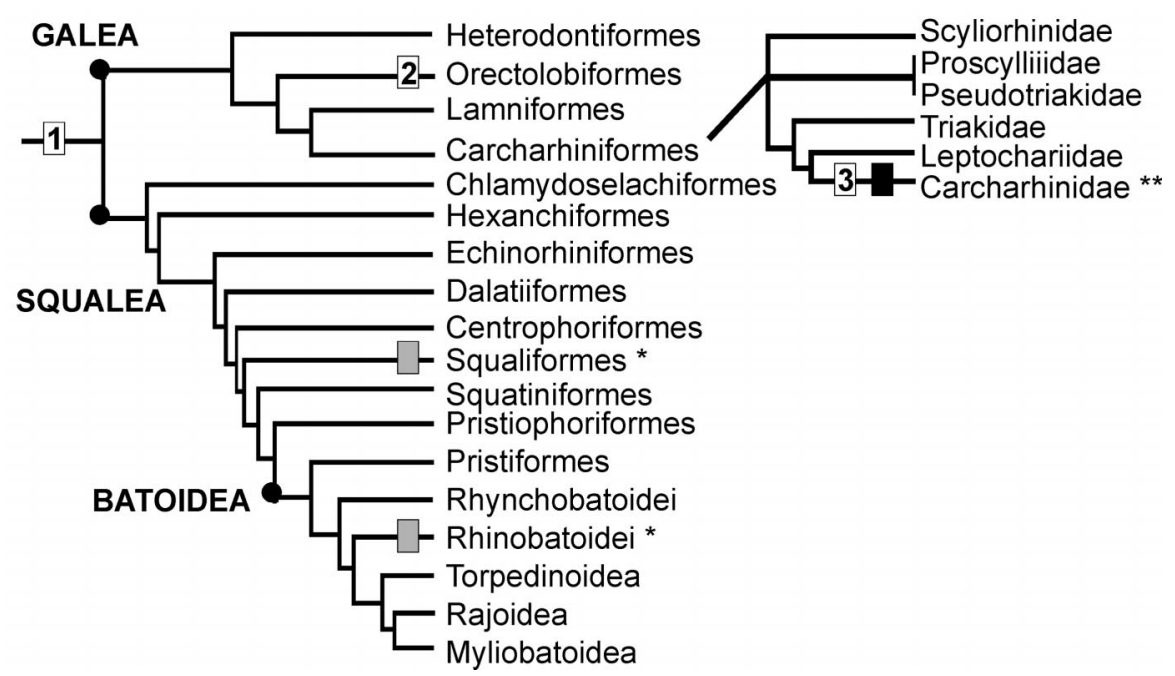

FIG. 4. Elasmobranch cladogram after Shirai (1996) with morphology and motor pattern of the levator palatoquadrati muscle mapped onto it according to Wiley et al. (1991). Black dots indicate the base of Galea, Squalea, and Batoidea. Numbered boxes indicate morphological differences: 1, dorsoventral orientation, postorbital cranium to posterior upper jaw; 2, anteroposterior orientation, postorbital cranium to anterior upper jaw; 3, anteroposterior orientation, antorbital cranium to posterior upper jaw. Colored boxes indicate function: gray, muscle active during upper jaw retraction; black, muscle active during upper jaw protrusion. Species with kinematic and electromyographic data used in this analysis are marked by an asterisk indicating the group in which the species belongs and the number of species examined per group.

Sphyrna tiburo (Fig. 2) (Motta et al., 1997; Wilga and Motta, 1998a, b, 2000). When the quadratomandibularis muscle contracts, it adducts the upper and lower jaws, and in doing so pulls the upper jaw away from the cranium towards the elevating lower jaw, effectively protruding it (Fig. 1). This mechanism would function most effectively if the lower jaw was held fairly stationary against a relatively large prey item while the unobstructed upper jaw is protruded (Moss, 1972).

\section{Evolution of protrusion mechanisms}

Mapping of morphological and functional characteristics onto an existing phylogeny can help to shed light on how changes in upper jaw protrusion may have evolved (Figs. 3, 4). Our criteria for concluding whether motor patterns are different is based on major qualitative differences concerning the synchrony of motor activity with specific kinematic events. For example, the onset of upper jaw protrusion and upper jaw retraction are distinct in time and so differences in motor activity and corre- sponding kinematic event are easily detected.

A single undivided preorbitalis muscle or ventral preorbitalis in taxa with a subdivided muscle is hypothesized to function as the ancestral upper jaw protrusion mechanism since it is possessed by all elasmobranch taxa. The quadratomandibularis muscle may have a greater role in assisting upper jaw protrusion in those taxa possessing a single preorbitalis, particularly in those with a relatively small preorbitalis muscle, such as Chlamydoselachus and hexanchiform sharks (Daniel, 1934; Smith, 1937). Although major structural changes have taken place in the preorbitalis muscle in elasmobranchs, the motor pattern is similar in the limited taxa that have been studied thus far, and in some batoids it has taken on the new function of lower jaw elevation. A second mechanism for upper jaw protrusion evolved in carcharhiniform sharks, involving the origin of a new muscle (dorsal preorbitalis) through subdivision of the preorbitalis muscle. The origin of this novel muscle and mechanism occurs while retain- 
ing the original preorbitalis (ventral) and its motor pattern. Some carcharhinid sharks acquired yet another mechanism for upper jaw protrusion through modification of the attachments of an existing muscle, the levator palatoquadrati, while retaining function in both preorbitalis mechanisms. It is unknown at what phylogenetic position this functional transformation took place within carcharhiniform sharks. In the latter case the structural change in morphology of the levator palatoquadrati muscle was accompanied by a radical alteration in motor pattern and function to that of jaw protrusion in some carcharhinid sharks from that of jaw elevation in other elasmobranchs (Motta et al., 1997; Wilga and Motta, 1998a, b, 2000).

Motor activity patterns during feeding in bony fishes and salamanders tend to show evolutionarily conserved patterns despite considerable morphological divergence (Sanderson, 1988; Wainwright et al., 1989; Westneat and Wainwright, 1989; Smith, $1994 a$ ). The case of the preorbitalis muscles in elasmobranchs supports this paradigm of conserved muscle patterns accompanying structural change. In contrast, the levator palatoquadrati muscle shows the opposite situation, in which structural change is accompanied by alteration of the ancestral motor pattern and functional divergence. The case of functional divergence in motor activity as a result of muscle duplication has been documented in a cyprinid fish (Ballintijn et al., 1972), a varanid lizard (Smith, 1982), and in several tetraodontiform fishes (Wainwright and Turingan, 1993; Friel and Wainwright, 1998, 1999). Tetraodontiform fishes with increased adductor muscle subdivisions are capable of functionally more complex jaw movements during feeding by modifying activity in individual subdivisions, which may provide finer control of the jaws (Friel and Wainwright, 1998, 1999). Similarly, sharks and rays with two or three mechanisms for protruding the jaw may may exhibit finer control and thus greater feeding success than those with fewer mechanisms. Interestingly, most known changes in upper jaw protrusion mechanisms have evolved in the carcharhiniform radiation. Sharks in the order
Carcharhiniformes contain $55 \%$ of all shark species and are the predominate group in nearshore tropical and warm temperate waters (Compagno, 1988). In addition, the family Carcharhinidae is one of the largest families of sharks (Compagno, 1988).

In summary, results based on four elasmobranch species show that the cranial muscles involved in lower jaw depression and elevation show a common pattern of motor activity during feeding. However, the muscles involved in upper jaw protrusion and retraction have had a more variable evolutionary history. The evolution of upper jaw protrusion mechanisms identified in elasmobranchs has involved modification of three musculoskeletal systems with different consequences for function and motor pattern: 1) the original preorbitalis muscle retains the ancestral function and motor activity even after it has physically subdivided; 2) the descendent preorbitalis (dorsal) muscle undergoes a change in insertion while retaining motor activity and overall function; and 3) a shift in origin of the levator palatoquadrati muscle accompanied by an alteration of motor activity and a change in function. Thus, we have identified three innovations in the evolution of the upper jaw protrusion system, two of which involve retention of motor activity and function, original preorbitalis and descendent preorbitalis, as is common in feeding mechanisms of bony fishes and salamanders (Shaffer and Lauder, 1985a, $b$; Wainwright and Lauder, 1986; Sanderson, 1988; Wainwright, 1989; Westneat and Wainwright, 1989; Lauder and Shaffer, 1993; Friel and Wainwright, 1998). In contrast, structural modification of the levator palatoquadrati muscle has been accompanied by an alteration in motor activity leading to a change in function. Such structural modification of musculoskeletal systems, leading to novel feeding mechanisms is characteristic of major functional shifts observed across broad phylogenetic taxa (Liem, 1979; Lauder, 1983; Wainwright et al., 1989), and has undoubtedly had major consequences for the evolution of vertebrate feeding mechanisms. 


\section{ACKNOWLEDGMENTS}

Authorship, other than the primary author, was determined by who would hold their hands in the shark tank the longest. We also acknowledge the time and assistance of the following people and institutions: Charles Manire, Carl Leur, Karel Liem, Mote Marine Laboratory, and Friday Harbor Laboratory. This research was supported by an NRC Ford Foundation Predoctoral Fellowship, University of Washington Research Grant for Friday Harbor Laboratory, Mote Marine Laboratory and USF Graduate Fellowship in Elasmobranch Biology to C.D.W. and NSF grant (DEB 9117371) to P.J.M. We thank Gavin Naylor for helpful comments and an anonymous reviewer who greatly improved this manuscript.

\section{REFERENCES}

Alexander, R. Mc. N. 1967. The functions and mechanisms of the protrusible upper jaws of some acanthopterygian fish. J. Zool. London 151:43-64.

Allis, E. P. Jr. 1917. The homologies of the muscles related to the visceral arches of the Gnathostome fishes. Quar. Jour. Mic. Sc. 62:303-406.

Allis, E. P. Jr. 1923. The cranial anatomy of Chlamydoselachus anguineus. Acta. Zool. 4:123-221.

Ballintijn, C. M., A. Van Den Berg, and B. P. Egberink. 1972. An electromyographic study of the adductor mandibulae complex of free-swimming carp $C y$ prinus carpio L. during feeding. J. Exp. Biol. 5: 261-283.

Bemis, W. E. and G. V. Lauder. 1986. Morphology and function of the feeding apparatus of the Lungfish, Lepidosiren paradoxa (Dipnoi). J. Morphol. 187: 81-108.

Clark, E. and D. R. Nelson. 1997. Young whale sharks, Rhincodon typus, feeding on a copepod bloom near La Paz, Mexico. Env. Biol. Fish. 50:63-73.

Compagno, L. J. V. 1973. Interrelationships of living elasmobranchs. In P. H. Greenwood, R. S. Miles, and C. Patterson (eds.) Interrelationships of fishes. Zool. J. Linn. Soc. Supp. 53:15-61.

Compagno, L. J. V. 1977. Phyletic relationships of living sharks and rays. Amer. Zool. 17:303-322.

Compagno, L. J. V. 1988. Sharks of the order Carcharhiniformes. Princeton University Press, Princeton, New Jersey.

Daniel, J. F. 1934. The elasmobranch fishes. University of California Press, Berkeley.

De Carvalho, M. R. 1996. Higher-level elasmobranch phylogeny, basal squaleans, and paraphyly. In M. Stiassney, L. Parenti, and D. Johnson (eds.), Interrelationships of fishes. Academic Press, New York.

Edgeworth, F. H. 1935. Cranial muscles of vertebrates. Cambridge University Press, Cambridge.

Ferry-Graham, L. A. 1997. Feeding kinematics of ju- venile swellsharks, Cephaloscyllium ventriosum. J. Exp. Biol. 200:1255-1269.

Ferry-Graham, L. A. 1998. Effects of prey size and mobility on prey-capture kinematics in leopard sharks, Triakis semifasciata. J. Exp. Biol. 201: 2433-2444.

Frazzetta, T. H. 1994. Feeding mechanisms in sharks and other elasmobranchs. Adv. Comp. Env. Physiol. 18:31-57.

Frazzetta, T. H. and C. D. Prange. 1987. Movements of cephalic components during feeding in some requiem sharks (Carcharhiniformes: Carcharhinidae). Copeia 1987:979-993.

Friel, J. P. and P. C. Wainwright. 1998. Evolution of motor pattern in Tetraodontiform fishes: Does muscle duplication lead to functional diversification? Brain, Behav. Evol. 53:159-170.

Friel, J. P. and P. C. Wainwright. 1999. Evolution of complexity in motor patterns and jaw musculature of tetraodontiform fishes. J. Exp. Biol. 202:867880 .

Lauder, G. V. 1983. Functional and morphological bases of trophic specializations in sunfishes (Teleostei, Centrarchidae). J. Morphol. 178:1-21.

Lauder, G. V. 1985. Aquatic feeding in lower vertebrates. In M. Hildebrand, D. M. Bramble, K. F. Liem, and D. B. Wake (eds.), Functional vertebrate morphology, pp. 210-229. Harvard University Press, Cambridge.

Lauder, G. V. 1991. Biomechanics and evolution: Integrating physical and historical biology in the study of complex systems. In J. M. V. Rayner and R. J. Wooten (eds.), Biomechanics and evolution, pp. 1-19. Cambridge University Press, Cambridge.

Lauder, G. V. and H. B. Shaffer. 1993. Design of feeding systems in aquatic vertebrates: Major patterns and their evolutionary implications. In J. Hanken and B. K. Hall (eds.), The skull: Functional and evolutionary mechanisms, Vol. 3, pp. 113-149. University of Chicago Press, Chicago.

Liem, K. F. 1979. Modulatory multiplicity in the feeding mechanism of the cichlids, as exemplified by the invertebrate pickers of Lake Tanganyika. J. Zool. London 189:93-125.

Liem, K. F. 1989. Functional design and diversity in the feeding morphology and ecology of air breathing teleosts. Prog. Zool. 35:487-500.

Lightoller, G. H. S. 1939. Probable homologues. A study of the comparative anatomy of the mandibular and hyoid arches and their musculature. Part I: Comparative morphology. Trans. Zool. Soc. Lond. 24:349-444.

Luther, A. 1909. Untersuchungen uber die vom N. trigeminus innervierte Muskulatur der Selachier (Haie und Rochen) unter Berucksichtigung ihrer Beziehungen $\mathrm{zu}$ benachbarten Organen. Acta. Soc. Sci. Fenn. 36:1-176.

Marinelli, W. and A. Strenger. 1959. Vergleichende Anatomie und Morphologie der Wirbeltiere. III. Lieferung Squalus acanthias. Vienna: Franz Deuticke.

Marion, G. E. 1905. Mandibular and pharyngeal muscles of Acanthias and Raia. Am. Nat. 39:891-920.

Moss, S. A. 1972. The feeding mechanism of sharks of the family Carcharhinidae. J. Zool. London 167:423-436. 
Moss, S. A. 1977. Feeding mechanisms in sharks. Amer. Zool. 17:355-364.

Motta, P. J. and C. D. Wilga. 1995. Anatomy of the feeding apparatus of the lemon shark, Negaprion brevirostris. J. Morphol. 226:309-329.

Motta, P. J. and C. D. Wilga. 1999. Anatomy of the feeding apparatus of the nurse shark, Ginglymostoma cirratum. J. Morphol. 241:33-60.

Motta, P. J. and C. D. Wilga. 2001. Advances in the study of feeding mechanisms, mechanics, and behaviors of sharks. In S. Gruber and T. Tricas (eds.), Biology and sensory biology of sharks: Past, present and future studies. Dev. Env. Biol. Fish. 20:131-156. Kluwer Academic Publishers, Dordrecht.

Motta, P. J., T. C. Tricas, R. E. Hueter, and A. P. Summers. 1997. Feeding mechanics and functional morphology of the jaws of the lemon shark, $\mathrm{Ne}$ gaprion brevirostris (Chondrichthyes, Carcharhinidae). J. Exp. Biol. 200:2765-2780.

Nakaya, K. 1975. Taxonomy, comparative anatomy and phylogeny of Japanese catsharks, Scyliorhinidae. Mem. Fac. Fish. Hokkaido Univ. 23:1-94.

Nobiling, G. 1977. Die Biomechanik des Kiefferapparates beim Stierkopfhai (Heterodontus portusjacksoni $=$ Heterodontus philippi). Adv. Anat. Embryol. Cell Biol. 52:1-52.

Pretlow-edmonds, M. A. 1999. Prey capture kinematics of the horn shark, Heterodontus francisci. Master's Thesis, Univ. of South Florida, Tampa.

Reilly, S. M. and G. V. Lauder. 1990. The evolution of tetrapod feeding behavior: Kinematic homologies in prey transport. Evolution 44:1542-1557.

Reilly, S. M. and G. V. Lauder. 1992. Morphology, behavior, and evolution: Comparative kinematics of aquatic feeding in salamanders. Brain, Behav. Evol. 40:182-196.

Robinson, M. 1999. Patterns of growth and the effects of scale on the feeding kinematics of the nurse shark, Ginglymostoma cirratum. Master's Thesis, Univ. of South Florida, Tampa.

Sanderson, S. L. 1988. Variation in neuromuscular activity during prey capture by trophic specialists and generalists (Pisces: Labridae). Brain, Behav. Evol. 32:257-268.

Shaffer, H. B. and G. V. Lauder. 1985a. Patterns of variation in aquatic ambystomatid salamanders: Kinematics of the feeding mechanism. Evolution 39:83-92.

Shaffer, H. B. and G. V. Lauder. 1985b. Aquatic prey capture in ambystomatid salamanders: Patterns of variation in muscle activity. J. Morphol. 183:273284.

Shirai, S. 1996. Phylogenetic interrelationships of Neoselachians (Chondrichthyes: Euselachii). In M. Stiassney, L. Parenti, and D. Johnson (eds.), Interrelationships of fishes. Academic Press, New York.

Smith, B. G. 1937. The anatomy of the frilled shark, Chlamydoselachus anguineus Garman. In E. W. Gudger (ed.), The Bashford Dean memorial volume archaic fishes. Am. Mus. Nat. Hist. NY 6: $331-520$.

Smith, K. K. 1994a. Are neuromotor systems conserved in evolution? Brain, Behav. Evol. 43:293305 .

Smith, K. K. 1982. An electromyographic study of the function of the jaw adducting muscles in Varanus exanthematicus Varanidae. J. Morphol. 173:137158.

Smith, R. J. 1994b. Degrees of freedom in interspecific allometry: An adjustment for the effects of phylogenetic constraint. Am. J. Phys. Anthropol. 93: 95-107.

Springer, S. 1961. Dynamics of the feeding mechanism of large galeoid sharks. Amer. Zool. 1:183-185.

Tiesing, B. 1895. Ein Beitrag zur Kenntris der Augen, Kiefer-, und Kiemenmuskulatur der Haie und Rochen., Jen. Zeitschr. f. Naturw. 30:75-126.

Tricas, T. C. and J. E. McCosker. 1984. Predatory behavior of the white shark (Carcharodon carcharias), with notes on its biology. Proc. Calif. Acad. Sci. 43:221-238.

Vetter, B. 1878. Untersuchungen zur vergleichenden Anatomie der Kiemen-und Kiefermuskulatur der Fische. Zeitschr. F. Naturw. 12:431-550.

Wainwright, P. C. 1989. Prey processing in haemulid fishes: Patterns of variation in pharyngeal jaw muscle activity. J. Exp. Biol. 141:359-375.

Wainwright, P. C. and G. V. Lauder. 1986. Feeding biology of sunfishes: Patterns of variation in the feeding mechanism. J. Linn. Soc. Zool. 88:217228 .

Wainwright, P. C., C. P. Sanford, S. M. Reilly, and G. V. Lauder. 1989. Evolution of motor patterns: Aquatic feeding in salamanders and ray-finned fishes. Brain, Behav. Evol. 34:329-341.

Wainwright, P. C. and R. G. Turingan. 1993. Coupled vs. uncoupled functional systems: Motor plasticity in the queen triggerfish, Balistes vetula (Teleostei, Balistidae). J. Exp. Biol. 180:209-227.

Wainwright, P. C. and R. G. Turingan. 1997. Evolution of pufferfish inflation behavior. Evolution 51:506518.

Westneat, M. W. and P. C. Wainwright. 1989. Feeding mechanism of Epibulus insidiator (Labridae: Teleostei): Evolution of a novel functional system. J. Morphol. 202:129-150.

Wiley, E. O., D. Siegel-Causey, D. R. Brooks, and V. A. Funk. 1991. The compleat cladist: A primer of phylogenetic procedures. Museum of Natural History, Univ. of Kansas, Lawrence.

Wilga, C. D. 1997. Evolution of feeding mechanisms in elasmobranchs: A functional morphological approach. Ph.D. Diss., Univ. of South Florida.

Wilga, C. D. and P. J. Motta. 1998a. Conservation and variation in the feeding mechanism of the spiny dogfish Squalus acanthias. J. Exp. Biol. 201: 1345-1358.

Wilga, C. D. and P. J. Motta. 1998b. Feeding mechanism of the Atlantic guitarfish Rhinobatos lentiginosus: Modulation of kinematic and motor activity. J. Exp. Biol. 201:3167-3184.

Wilga, C. D. and P. J. Motta. 2000. Durophagy in sharks: Feeding mechanics of the hammerhead, Sphyrna tiburo. J. Exp. Biol. 203:2781-2796.

Wilga, C. D., P. C. Wainwright, and P. J. Motta. 2000. Evolution of jaw depression mechanics in aquatic vertebrates: Insights from Chondrichthyes. Biol. J. Linn. Soc. 71:165-185.

Wu, E. 1994. A kinematic analysis of jaw protrusion in orectolobiform sharks: A new mechanism for jaw protrusion in elasmobranchs. J. Morphol. 222: 175-190. 